\title{
Study on the Application of Ming and Qing Dynasties Literati Painting on Interior Design
}

\author{
Zhenyan Ye \\ Guangdong Province Zhuhai College of Jilin University, Zhuhai, Guangdong, 519041
}

Keywords: Ming and Qing Dynasty, Interior Design Art, Literati Painting

\begin{abstract}
With the social and economic development, people's demand for design is increasing day by day. However, some misunderstandings in the design of our modern indoor environment also emerge. For example: 1. The desalination of historical precipitation and the lack of humanistic spirit; 2. The disconnection between modernity and tradition; 3 . The function and form are greater than the aesthetic feeling. Therefore, it is one of the goals of many modern interior environment designers to probe how to realize localization and regionalization of modern indoor environment design in our country. This study finds that to change this situation, it needs to change from a deeper level of design spirit. Especially, the aesthetic concept of modern interior environment design should be consistent with our traditional aesthetic concept. Because of the extensive and profound Chinese traditional aesthetic system, Corner: the concept of literati painting to start with our modern interior design can learn from. Through the analysis of the development process of the literati painting and the guiding ideology of philosophy, it finds out the "artistic conception" in the literati's aesthetic appreciation and the realm of "lightness" and "emptiness" advocated in the artistic conception of the painting. Looking for this picture "mood" that can be used for reference to the design of modern interior environment, and analysis of the composition of the literati in this aesthetic concept program rules, color system, a large number of repetitive scholarly ethics subject, As well as the uniqueness of literati painting: the combination of poetry, calligraphy, painting and printing, etc. How to apply these features to the design of our modern interior environment.
\end{abstract}

\section{Introduction}

The development of literati painting in the Ming and Qing Dynasties is both rich and complex. The research and exploration on this issue have a great significance in studying the history of Chinese painting and the development of modern Chinese painting. In the past, there were many case studies of Ming and Qing dynasties of literati paintings, but there were only a few books on the overall theory of literati painting in the Ming and Qing dynasties. In the case study, there are 16 books of Ming and Qing Chinese masters edited by Zhou Jianyin. They are the research on literati painting in the Ming and Qing Dynasties from the case studies of literati painters and painting schools. The Wumen School, Xu Wei, Dong Qichang, , Four kings, eight strange Yangzhou, etc. have been widespread concern. Xu Jianrong's "Ten Studies of Yuan, Ming and Qing Dynasties' Paintings" also made a case study of Tang Yin, Xu Wei, Dong Qichang and "Yangzhou Baigai". There are many more personal biographical studies on Ming and Qing scholar artists. The overall theoretical study of Ming and Qing literati painting is represented by the "New Trend of Literati Painting of Ming and Qing Dynasties" by trees. From the history of painting and calligraphy to the works and painters, the trees are examined one by one from the aspects of emotion and technique, subject matter and style, and compared with each other Artistic techniques, in the comparison with the previous art analysis of literati paintings in Ming and Qing dynasties content and originality factors.

\section{Deconstruction of the Artistic Field of Literati Painting in Ming and Qing Dynasties}

As Danny, an art critic, put it: "To understand a work of art, an artist, a group of artists must correctly conceptualize the spirit and customs of the age to which they belong, which is the last 
explanation of art and the basic reason for everything In order to understand the characteristics of literati paintings in Ming and Qing Dynasties more fully and thoroughly, it is necessary to understand the social and cultural environment and academic background of the time. Ming and Qing Dynasties already in the late feudal society in China, rigid decay, apathetic. The political manifestation of the monarchy intensified, especially in the late Qing Dynasty, monarchy reached its peak. The "Neo-Confucianism", which is produced and serves the feudal ruling class during the monarchy's monarchy, imprisons people's thoughts all the time. Because of the various conditions and limitations of the political background, cultural environment and so on, the distance between literati paintings in Ming and Qing dynasties is still far and away from the brushwork. Survival and feelings, the pursuit of self-esteem freedom and the awareness of human life affirmed and valued. Compared with the early literati paintings, literati and paintings in the Ming and Qing dynasties marked the artist's subjective consciousness and life experience more intensely, and paid more attention to the exposition and publicity of "I", "Xin" and "Xing" in the works.

\section{The Aesthetic Features of Literati Painting and Artistic Conception in the Design of Modern Interior}

Indoor environment design development to today, he covers more and more, more and more detailed classification. Such as advertising design, logo design, packaging design, etc., in these categories and in more detail into a number of small categories, each with its own characteristics and design requirements. Can not be described in detail here, a few types of which are listed a little analysis.

In the modern design of posters, posters are no longer simply stuck in the early "advertised" in the primary stage of information delivery, advertising because of modern business can create considerable profit value, establish a positive corporate culture and More and more accepted by the public. As a result, there is an increasing demand for information beyond its basic function. Posters posters have a certain timeliness, faster updates, broadly divided into a commercial category, 2 public welfare, 3 arts and culture class. According to the different categories have different appeal points in commercial advertising is divided into product advertising and corporate image ads. The mood of creating a picture in the advertisement poster works has become the focus of the present design. In the "free" series of works of Mr. Jin, the conventional philosophy of "walking," "sleeping," "eating," and others is given an indifferent philosophical thinking which quickly draws the viewer's attention and introduces it into a free and easy way. Flowing clouds of wonderful mood.

Signs are visual symbols that represent and represent things or information, act as symbols and signatures, and convey the meaning, message, and emotion of something. With the development of the times, the function of the logo in modern design has been continuously extended. As a symbol, it has played the role of distinguishing you from me, establishing brand image, creating enterprise value and spreading culture. The establishment of the logo represents the establishment of the corporate image itself, so the logo is often only subtly adjusted in the same style with very few large-scale changes. In the logo design because of the characteristics of the mark itself, the general area smaller, and strive to concise. However, it is precisely for this reason that there are similarities with the graphic abstraction in literati painting and the artistic conception in simplified form and in the form of simple images; it is conducive to using beautiful curves, symbolic figures and simple colors for creation

\section{The Use of Modern Interior Design to Aesthetic Conceptions of Scholars}

Although the composition of literati paintings is seemingly ever-changing and varied, it is also a rule-based one. In the long-term development and evolution of Chinese paintings, the compositional rules of the composition in line with their own aesthetic needs have been established. This unique compositional law also plays an important role in the performance of "artistic conception" in literati paintings. In his exploration of "the origin of Chinese landscape painting", Gorty proposed that the 
traditional Chinese painting developed from the traditional to the simple. Composition from the panorama to the local, corner development trend. In the Yuan Dynasty, Rao naturally pointed out the importance of composition in artistic creation. He pointed out that the first taboo was unforgivable: "There is also a need to open and close, This is the first thing to do. "Just as the pursuit of gorgeousness in the aesthetic realm is attributed to dullness, this notion is reflected in the composition of the literati painting and also sought to simplify and multiply it, Literati Painting Fully Embodies "Simple" Realm in Composition. Literati composition features common in the following areas:

Different from the perspective of Western painting, the Chinese perspectives use scatteroscopy, which is not limited by space or observation. The picture angle up and down at any time change. In the landscape painting is the use of scattered perspective method to look down, looking up, head-up, close to take, far perfect combination of perspective, between the performance of thousands of miles mountains and rivers.

Relevance also has the individual's freedom, the distribution appears to be random, chance, there are certain rules to be found, the picture is full of sense of space and movement. Showing a more casual and easy way of composition, compared with the traditional rules and rational single-point perspective composition, more in line with the modern pursuit of relaxed and slow-paced concept. The formation of irregular scatter points of various elements on the screen can create a casual and relaxing visual effect, which makes people feel relaxed and smooth. Moreover, a variety of visual levels are formed on the screen to guide the viewers' flow of sight.

Literati composition through the "business location" in order to achieve "vivid" effect. This can be achieved by creating "potential" in the picture. The "potential" here can be regarded as the specific situation of the whole picture and the tendency of the whole picture as a whole. The Chinese painting is very particular about the "placement". Potential on the screen can be divided into horizontal, vertical, oblique, Qu potential, group potential and so on. And the size of the points, that is, the overall relationship between the picture and the local, is the picture of the overall and local relations, the overall trend is determined, one of the small movements can be contrary to the great momentum of the place, However, it can not affect the overall status of the major movements on the screen. And through the small move and the big move contrary to the movement, the picture is more lively. This is somewhat similar to the "special" "specific" composition we commonly use in the principles of the design of indoor environments. In the process of "laying", we often use the methods of actual situation, contrast, distance and echoes to achieve the changes of "wanting to go first and right,

The ancients stress "the main guest North Korea." That the primary and secondary relationships should be clear, the composition of the screen as well, in the picture to determine a center, that is, the main body, from the position is more conducive to the full performance of the main body. Other objects exist as objects and serve as echoes with the subject. The Lord and the guests are interdependent and seamless. Only in the composition of the guest host clear, the screen can both the level and focus, can not be "overwhelming." When the composition of the main body position and the relationship with the object to be arranged according to the design theme, the method eclectic. Such as the collection of moving lines point or point of intersection, the image of the dense center of the formation of the visual center.

Blank is the composition of the scholar painting is very important, but also a unique composition technique. The literati painting technique has always had the feature of taking the gods and pays more attention to the subjective spirit than the complete portrayal of the image form. With the simplification of literati painting as a unique means to take the most essential features of the image, with the theme of dispensable content. The "blank" work is different from the unfinished work, where the blank space on the paper is also an important part of the screen. Both set off the theme of the screen, but also the formation of visual extension, resulting in the scene of the picture association. Huang Binhong said: "The painting not only depends on the actual situation of the painting, but also on the blank space of the painting." The use of the technique of leaving a blank in the interior design can play a very good effect. On the one hand, it can highlight the theme, White 
background of the main subject, in line with the modern design of the pursuit of efficient communication of information needs, while the performance of the screen mood, works to enhance the quality of realm also has a significant role, both in line with the Chinese subtle expression of habits, but also to the audience Great visual and imaginative space.

\section{Conclusion}

Chinese literati painting has a high artistry. On the one hand, its aesthetic conception not only inherits the traditional Chinese aesthetic spirit but also has its unique aesthetic concept. On the other hand, In the "elegant" full performance, until today, "clear water out of hibiscus, natural to carving" is still our highest "beauty" rating. The characteristics of our modern interior design determine the versatility of the design work, both the designer's personal artistic language expression, but also from the audience's aesthetic preferences, and even in life has been highly modern and international today, Our traditional culture is still deeply imprinted on the people's aesthetic concepts. As the concept comes from the design of our country's modern interior environment in the west, how to integrate culture with our national culture, to realize the design behavior and to design the localization of the works is a major issue that we must face.

\section{References}

[1] Gu Ping. "Royal Sponsorship" and the Causes of Landscape Style of "Courtyard" in the Southern Song Dynasty [J]. Acta Literature and Art Research, 2003 (04)

[2] Dou Zhongjun .Receiving the tradition from the rise and fall of Northern Song dynasty academy painting style [J]. Northwest Fine Arts. 2003 (03)

[3] Li Yi .Southern Song Dynasty courtyard landscape painting style of the social reasons for exploration [J]. Jingmen Vocational and Technical College .2006 (02)

[4] Wang Jihua. Who is the Magic? Reflections on the decline of the body painting [J] .Art Research. 2006 (01)

[5] Zhou Qingbo.On the Interpretation of the Style of "Courtyard" Landscape Paintings in South Song Dynasty [J]. Journal of Zhengzhou University (Philosophy and Social Science), 2006 (04)

[6] Lu Zhiqiang. Freehand body painting of the Song Dynasty [J]. Fujian Arts. 2006 (05)

[7] Li Lei. Viewpoints on the Transmission of the Body Paintings in Song Dynasty [J]. Journal of Huzhou Teachers College. 2007 (03) 